Review

\title{
Contaminants of Emerging Concern Removal by High-Energy Oxidation-Reduction Processes: State of the Art
}

\author{
Andrea G. Capodaglio \\ Department of Civil \& Environmental Engineering, University of Pavia, 27100 Pavia, Italy; capo@unipv.it; \\ Tel.: +39-0382-985-591 or +39-0382-985-592
}

Received: 29 September 2019; Accepted: 22 October 2019; Published: 27 October 2019

Featured Application: The application of electron beam and plasma treatment of water and wastewater for complete degradation of contaminants of emerging concern from these media is discussed.

\begin{abstract}
The presence of 'emerging contaminants', i.e., chemicals yet without a regulatory status and poorly understood impact on human health and environment, in wastewater and aquatic environments is widely reported. No established technology, to date, can simultaneously and completely remove all these contaminants, even though some Advanced Oxidation Processes (AOPs,) have demonstrated capacity for some degradation of these compounds. High-energy, radiolytic processing of water matrices using various sources: electron beam (EB), y-rays or non-thermal plasma (NTP) have shown excellent results in many applications, although these remain at the moment isolated examples and scarcely known. High-energy irradiation constitutes an additive-free process that uses short-lived, highly reactive radicals (both oxidating and reducing) generated by water radiolysis, which can instantaneously decompose organic pollutants. Several studies have demonstrated its effectiveness, as a stand-alone process or combined with others, in the rapid decomposition (up to complete mineralization) of organic compounds in pure and complex solutions, and in the removal or inactivation of microorganisms and parasites, without production of leftover residual compounds in solution. High-energy oxidation processes (a.k.a. Advanced Oxidation \& Reduction Processes-AORPs) could have a primary role in future strategies addressing emerging contaminants.
\end{abstract}

Keywords: AORPs; high-energy process; radiolysis; contaminants of emerging concern; AOPs; water; wastewater; electron beam; $\mathrm{y}$-rays; plasma

\section{Introduction}

Chemical synthesis of both organic and inorganic compounds plays a paramount role in modern industrial production, as a process by which substances currently used in daily life are obtained. Its products impact everyday life directly and indirectly, creating the need for methods for their safe disposal/decomposition prior to emission to ambient media. Novel organic micro-contaminants include contaminants of emerging concern (CECs), pharmaceuticals and personal care products (PPCPs), and metabolites thereof excreted after human or animal assumption. These have been recently detected in surface waters worldwide [1,2] and some are suspected endocrine disruptors (EDs), with potential, direct consequences on human health [3]. It has been estimated that about $80 \%$ of the 16,000 tons/year of PPCPs discarded in Germany end up flushed in toilets or disposed of with household waste, and may thus find their way into natural waters [4]. 
Detection of these pollutants in the environment, and especially in water supply systems [5], from where they could negatively affect individuals' health and cause the spread of antibiotic resistance phenomena [6] is an important issue not yet satisfactorily addressed. More important, however, is the identification of suitable processes for their minimization or, possibly, complete decomposition in the containing solution. In currently operating wastewater treatment plants (WWTPs), emerging pollutants and their metabolites could be partly transformed by biological or chemical reactions, or surface processes (e.g., adsorption on solid phases). Several studies have proved that the disappearance rates of many compounds observed in solution (determined as the difference of influent and effluent concentrations) may not imply per se a correspondingly equal rate of complete degradation (mineralization), as transformation byproducts whether in the effluent, or accumulated within a different phase (i.e., excess process sludge) are often revealed $[7,8]$. These byproducts may sometimes be even more hazardous than the original compound. Furthermore, often biological or chemical transformation pathways of these compounds are still undetermined [9].

In such instances, treatment processes merely shift any environmental risk to a different triggering molecule or exposure medium. Effective technologies for their total removal from solutions are not yet fully established, nor capable to remove simultaneously all possible contaminants. Some processes have demonstrated capacity to remove some, and are adopted on case-by-case approaches. More frequently, for removal of these pollutants, processes like biodegradation [10] and Advanced Oxidation Processes (AOPs) [11] are adopted. The latter is a broad category including both homogeneous and heterogeneous processes, such as ultraviolet (UV) photolysis, Fenton, electrochemical, sonochemical, supercritical water or wet air oxidation, often in combination with chemical catalysts (e.g., $\mathrm{TiO}_{2}$ ) or oxidizers (e.g., $\mathrm{O}_{3}, \mathrm{H}_{2} \mathrm{O}_{2}$ ). Mainstream AOPs may still result in the above mentioned drawbacks, although they may comply with certain water reuse regulations for specific compounds. Moreover, as concentrations of these chemicals are usually very low, specific treatment costs (cost per unit mass removed) generally turn out to be quite high [12].

Research for more effective CEC compound destruction technologies is ongoing. Emerging technologies such as electron beam (EB) and non-thermal plasma (NTP) have recently been proposed as suitable for this purpose $[13,14]$ and could provide viable alternatives to the former. This paper discusses the state-of-the-art (SOTA) of these technologies for the treatment of supply and used water.

\section{Materials and Methods}

Both EB and NTP technologies, although often neglected by the mainstream water and wastewater literature [15] belong to the AOP category (also defined as "aqueous phase oxidation"), since their effects are based on the in situ generation of oxidative, highly reactive radicals for the degradation of organic compounds in a solution. Both processes have very specific peculiarities that may render them more effective and efficient than their currently adopted counterparts.

\subsection{Electron Beam Radiolysis Process}

EB irradiation of a solution is a form of "high-energy oxidation" based on the use of highly energy-charged electrons capable of generating at the same time strong oxidizing and reducing radicals by splitting water molecules, including: superoxides (a.k.a. hyperoxides, $\left.\mathrm{O}_{2}^{-}\right)$, hydroxyl $(\cdot \mathrm{OH})$ and hydrogen $(\cdot \mathrm{H})$ radicals, solvated electrons $\left(\mathrm{e}^{-}\right.$aq $)$, and others. These species are very reactive (much stronger oxidation potentials than $\mathrm{O}_{3}$, as shown in Table 1 [4], and short-lived (half-lives are in the order of $10 \mu \mathrm{s}$ at $10^{-4} \mathrm{M}$ concentration), and are hence capable of carrying out rapid and extended molecular degradation, potentially to complete mineralization (depending on the absorbed dose and irradiation intensity). For these specific characteristics, radiolysis-based processes have been classified by researchers as Advanced Oxidation-Reduction Processes (AORPs), a subset of AOPs [16]. It should be noted that other irradiation technologies (i.e., gamma irradiation) will have similar final pollutant degradation effects [17], however, their reaction rates are much lower, due to lower achievable 
irradiation dose-rates (by one to three orders of magnitude), so for application purposes EB technology is currently preferable (Table 2).

Table 1. Oxidation potential of some common oxidizing molecules and radicals [4].

\begin{tabular}{lc}
\hline \multicolumn{1}{c}{ Species } & Potential, $\mathbf{E}^{\circ}\left(\mathbf{V}, \mathbf{2 5}{ }^{\circ} \mathbf{C}\right)$ \\
\hline Hydroxyl radical $(\cdot \mathrm{HO})$ & 2.86 \\
Atomic oxygen $(\mathrm{O})$ & 2.42 \\
Ozone molecule $\left(\mathrm{O}_{3}\right)$ & 2.07 \\
Hydrogen peroxide $\left(\mathrm{H}_{2} \mathrm{O}_{2}\right)$ & 1.78 \\
Chlorine $\left(\mathrm{Cl}_{2}\right)$ & 1.36 \\
Oxygen molecule $\left(\mathrm{O}_{2}\right)$ & 1.23 \\
\hline
\end{tabular}

Table 2. Achievable (measured) dose-rates of Gamma and EB radiation sources [4].

\begin{tabular}{lcc}
\hline \multicolumn{1}{c}{ Radiation source } & Energy $(\mathbf{k W})$ & Calculated dose-Rate $\mathbf{( M G y / h )}$ \\
\hline${ }^{60} \mathrm{Co} \gamma$-source & & \\
\hline $0.5 \times 10^{6} \mathrm{Ci}^{*}$ & 0.18 & 0.65 \\
$1.0 \times 10^{6} \mathrm{Ci}$ & 0.36 & 1.30 \\
\hline Electron Beam $(\mathrm{EB})$ & & \\
\hline $1 \mathrm{~mA}, 1 \mathrm{MeV}$ & $7.2 \times 10^{3}$ & $3.6 \times 10^{5}$ \\
$10 \mathrm{~mA}, 10 \mathrm{MeV}$ & 100 & $1.8 \times 10^{6}$ \\
$50 \mathrm{~mA}, 10 \mathrm{MeV}$ & 500 &
\end{tabular}

Table 3 summarizes overall possible EB radiation effects in a solution after radiolysis-induced generation of radicals. Such radical-generating reactions occur within a $10^{-6}-10^{-12}$ sec time span, and the degradation of organic molecules by the radicals occurs in that time frame. It should be noted that if radicals find no suitable molecules to react with (e.g., in pure water), an equally fast, reverse reaction takes place, and water molecules are recombined with no residues left in solution.

Table 3. Possible action mechanisms of EB-generated radicals in a water medium.

\begin{tabular}{|c|c|c|c|c|c|}
\hline \multicolumn{6}{|c|}{ Components in Solution } \\
\hline & Metals & & Organic Molecules & & Pathogens and Algae \\
\hline- & $\begin{array}{l}\text { Reduction (most species } \\
\text { become insoluble } \\
\text { and precipitate) }\end{array}$ & - & $\begin{array}{l}\text { Complete decomposition (mineralization to } \\
\mathrm{CO}_{2}, \mathrm{H}_{2} \mathrm{O} \text { ) } \\
\text { Partial decomposition (to forms more } \\
\text { susceptible to biodegradation or other) } \\
\text { Organic solids cell walls destruction (promotes } \\
\text { coagulation and improves sludge dewatering) } \\
\text { Removal/degradation of toxic groups } \\
\text { (improves biodegradability and lowers } \\
\text { intake risks) } \\
\text { Removal of odors \& color causing molecules }\end{array}$ & - & $\begin{array}{l}\text { Disinfection and destruction (incl. } \\
\text { viruses and cysts, no residual } \\
\text { toxicity due to chlorination) } \\
\text { Inhibits algal growth in effluents }\end{array}$ \\
\hline
\end{tabular}

\subsubsection{EB Technology}

A typical EB device is illustrated in Figure 1: a cathode releases electrons under high vacuum, and these are accelerated by high voltage (DC) or radiofrequency sources, while electrostatic or magnetic fields focus and deflect the direction of their beam on a window carved in thin metal foil. Electrons escape this window with energy proportional to applied voltage, in quantity that depends on cathodic current. Both voltage and current can be adjusted to control beam penetration depth in the exposed medium (proportional to energy) and dose rate (proportional to current), respectively [18]. Aside from the amount of energy involved, the entire apparatus is conceptually quite similar to a cathodic-tube television set. 


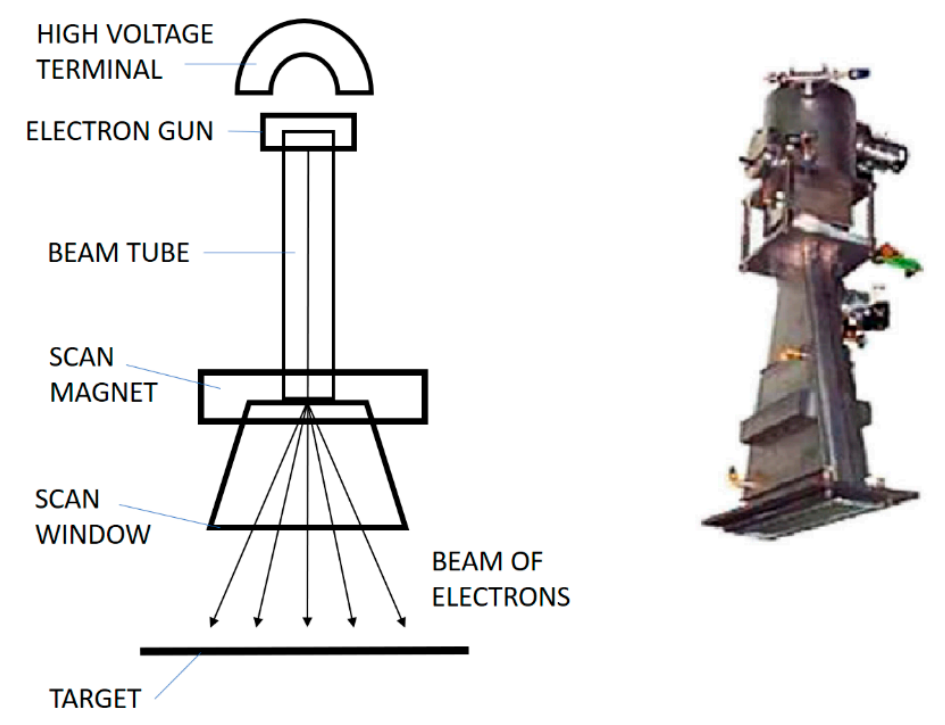

Figure 1. Modern EB apparatus: schematics (left) and view (right).

Emitted energy is measured in electronvolt $(\mathrm{eV})$ units (defined as the amount of energy gained by the charge of an electron across an electric potential difference of $1 \mathrm{~V}$ ). As the electronvolt is a very small quantity (approximately $\left.1.602 \times 10^{-19} \mathrm{~J}\right)$, the $\mathrm{keV}\left(10^{3} \mathrm{eV}\right)$ is commonly used as reference unit. EBs used in water/wastewater applications are usually rated in the range $500 \mathrm{keV}-1.2 \mathrm{MeV}$, but may also reach $10 \mathrm{MeV}$ in older models or very large applications. Irradiation dose is measured in Grey (Gy, defined as absorption of $1 \mathrm{~J}$ of radiation energy by $1 \mathrm{~kg}$ of matter). Use of high DC voltage allows conversion of input AC to beam power with high efficiency (>95\%), making this one of the higher energy-efficient processes available (by comparison, last generation UV systems applied in water disinfection show conversion efficiencies-electric to UV- of about $30 \%$ ).

A practical limitation to EB processes' use is a limited water penetration (from 1 to $5 \mathrm{~cm}$, depending on beam energy) of the beams, hence special delivery devices are needed to allow effective processing of continuously flowing streams, such as weir/cascade systems, up-flow stream systems, and nozzle-type injection [15].

\subsubsection{Radiolytic Process Kinetics}

In diluted aqueous solutions, practically all irradiated energy is absorbed and contributes to water radiolysis, without affecting the solution's radioactivity. In addition to the radicals previously mentioned, also other, less reactive, species such as $\mathrm{H}_{2}, \mathrm{H}_{2} \mathrm{O}_{2}$ and $\mathrm{H}_{3} \mathrm{O}^{+}$can be formed. In pure solutions, the reaction rates of $\mathrm{OH}$-radicals with most organic species are approximately $10^{9}$ times higher than $\mathrm{O}_{3}$ reaction rates [19]. As with traditional AOPs, in complex solution matrixes, naturally present compounds may function as radical scavengers (e.g., $\mathrm{O}_{2}, \mathrm{HCO}_{3}{ }^{-}, \mathrm{CO}_{2}^{-}, \mathrm{Cl}^{-}, \mathrm{NO}_{2}{ }^{-}, \mathrm{NO}_{3}{ }^{-}$, DOC), decreasing overall process efficiency or requiring a higher energy input.

Kinetic models can be applied to monocomponent solutions with appropriate individual reaction constants for the preliminary estimation of radiolytic degradation processes. Decomposition yields will change as function of initial concentration, $\mathrm{pH}$, and other operating conditions. However, pollutants decomposition kinetics in complex solutions may significantly vary from theoretical ones as result of interfering phenomena (radical scavenging, components cross-interferences, matrix effects). From a practical aspect, such effects could only be determined experimentally, as normally occurs for application of conventional AOPs in current applications.

Table 4 summarizes the role and efficiency of the main radicals generated by water radiolysis in the degradation of CECs and known hazardous pollutants. It is interesting to see how the combination effects of the different radical species generated by irradiation may enhance the overall treatment effectiveness. 
Table 4. Organic compounds removal efficiencies by radicals formed due to water radiolysis (modified from [15]).

\begin{tabular}{|c|c|c|c|c|c|c|}
\hline \multirow{2}{*}{$\begin{array}{c}\text { Compound } \\
\text { Target Organic Compounds * }\end{array}$} & \multicolumn{3}{|c|}{ Bimolecular Rate Constants $\left(\mathbf{M}^{-1} \mathbf{s}^{-1} \mathbf{1 0}^{9}\right)$} & \multicolumn{3}{|c|}{ Relative Importance of Species (\%) } \\
\hline & $\cdot \mathrm{OH}$ & e-aq & $\cdot \mathrm{H}$ & $\cdot \mathrm{OH}$ & $\mathrm{e}-\mathrm{aq}$ & $\cdot \mathrm{H}$ \\
\hline MTBE & 2 & 0.0175 & 0.0001 & 99 & 1 & 0 \\
\hline Trichloroethylene & 2.9 & 1.9 & NF & 61 & 39 & 0 \\
\hline Tetrachloroethylene & 2 & 1.3 & 5 & 46 & 29 & 25 \\
\hline Benzene & 7.6 & 0.009 & 0.91 & 97 & 01 & 3 \\
\hline Toluene & 5.1 & 0.011 & 2.6 & 90 & 0.1 & 10 \\
\hline Ethylbenzene & 7.5 & $\mathrm{NF}$ & NF & 100 & 0 & 0 \\
\hline$o$-Xylene & 6.7 & NF & 2 & 94 & 0 & 6 \\
\hline Chloroform & 0.054 & 11 & 0.073 & 0.4 & 99 & 0.1 \\
\hline $\mathrm{CHBrCl}_{2}$ & NF & 21 & NF & 0 & 10 & 0 \\
\hline $\mathrm{CHBr}_{2} \mathrm{Cl}$ & NF & 20 & $\mathrm{NF}$ & 0 & 10 & 0 \\
\hline Bromoform & 0.11 & 26 & 1.9 & 0.5 & 97.5 & 2 \\
\hline Ethylene dibromide & 0.26 & 14 & NF & 2 & 98 & 0 \\
\hline $\mathrm{DBCP}$ & 0.73 & NF & NF & 100 & 0 & 0 \\
\hline NDMA & 0.33 & NF & NF & 100 & 0 & 0 \\
\hline Atrazine & 2.6 & NF & NF & 100 & 0 & 0 \\
\hline Simazine & 208 & $\mathrm{NF}$ & $\mathrm{NF}$ & 100 & 0 & 0 \\
\hline
\end{tabular}

* Rates determined in synthetic, mono-component solutions-NF not found.

\subsection{Nonthermal Plasma Processes}

In contrast to EB technology, which relies on electrons generated by an external source, NTP usually employs a corona discharge generated by high-voltage electrical pulses, exciting electrons present in ambient air above the liquid solution. The ionization induced by the electrical pulses produces singlet oxygen atoms which then generate ozone and hydroxyl radicals. Alternative NTP configurations may use dielectric barrier discharges, or create corona discharges in aerosols or within the water matrix itself, without substantial differences $[14,20,21]$. The generated low-intensity UV light wavelengths belong in the $250-1000 \mathrm{~nm}$ range, with spectral peaks in wavelengths associated with radical formation. NTP is considered a highly efficient technology since very little energy is lost in thermal form, most being used in the excitation of electrons [22].

As with EB, one significant benefit of NTP is that oxidants are generated without the addition of chemicals, which is costly, or the need for UV lamps which, in addition to low energy conversion efficiency, require significant maintenance and which effect may be severely affected by turbidity or solution absorbance. Initially, NTP was extensively investigated to achieve degradation of volatile organic compounds (VOCs) [23] and gaseous effluents treatment [24]. Lately, NTP water and wastewater treatment application studies are gaining popularity due to the limitations associated with conventional AOPs.

\subsubsection{Non-thermal Plasma Technology}

NTP technology is to date confined to low-flow, mostly bench scale applications, due to its limited water penetration, which demands a thin-flow configuration, similarly to the situation of EB systems. It can be expected that technical solutions similar to those adopted with the latter could promote upscaled NTP applications. One of the better known pilot-scale NTP units reported in literature is an "electrode-to-plate" prototype described by Locke [21], consisting of two reactors in series. In the 1st reactor, water flows in a thin film (about $5 \mathrm{~mm}$ ) along an electrode (anode), while exposed to high-voltage pulses from carbon fiber (cathode). The space between carbon electrode and water surface may be adjusted for process optimization according to each specific water matrix. Electric pulses were characterized by frequencies in the range $500-1000 \mathrm{~Hz}$, maximum voltage of $8.0 \mathrm{kV}, 100 \mathrm{~A}$ current, $1 \mathrm{~J}$ energy, and rise time of $18 \mathrm{~ns}$. The pilot unit scheme is illustrated in Figure 2. 


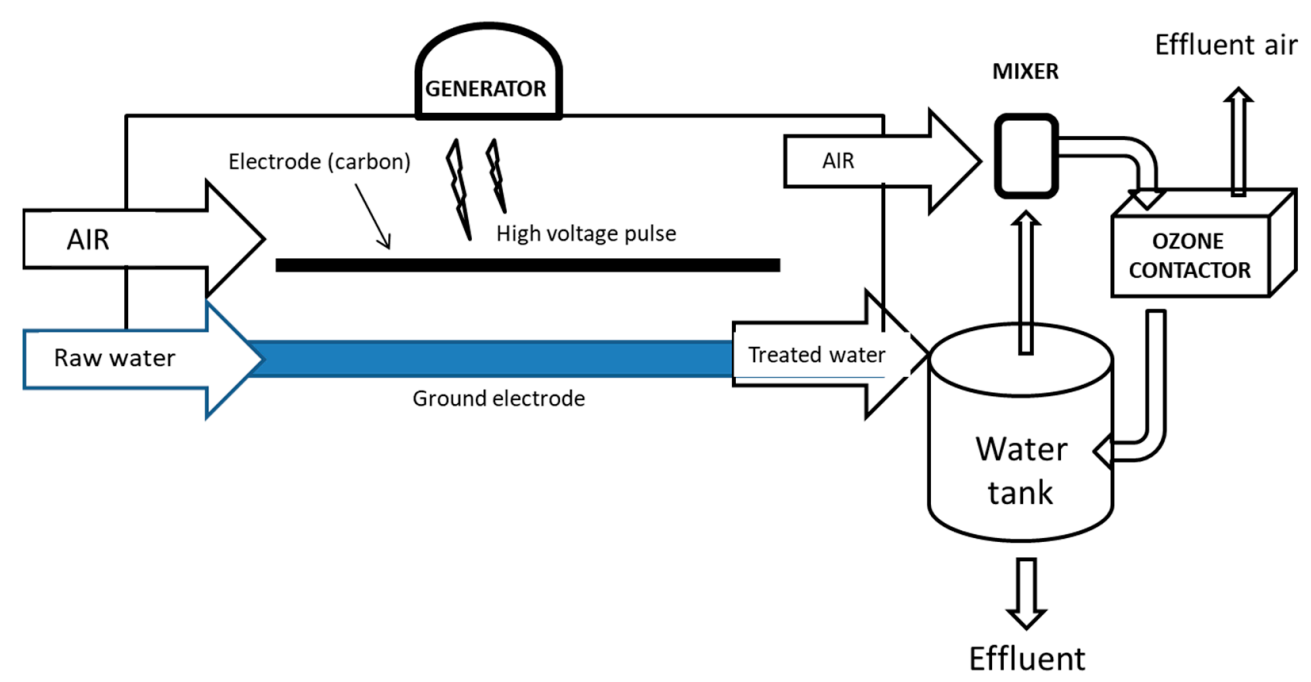

Figure 2. Schematics of a NTP unit. non-thermal plasma (NTP).

After flowing through the 1st reactor, water is stored in a side tank. Before entering an ozone contactor (2nd reactor) for additional contact time, an injector system mixes ozone-rich air (about $2 \mathrm{~g} / \mathrm{m}^{3}$ ) from the 1st reactor headspace with a fraction of the treated water before discharge. Excess air from the contactor is extracted and sent to an ozone quenching unit before discharge into the atmosphere. Hydraulic residence times (HRT) in reactor and storage tank vary depending on flow rate, whereas in the ozone contactor HRT remains relatively constant. For flows between 10 and $15 \mathrm{~L} / \mathrm{min}$, tested HRTs were approximately $0.5 \mathrm{~min}$ (reactor), 4-7.5 min (storage tank) and $1.5 \mathrm{~min}$ (ozone contactor), respectively.

The level of treatment can be adjusted by adjusting the frequency within the operating range and/or voltage (up to $40 \mathrm{kV}$ ) of electrical pulses. Depending on voltage and frequency, a reactor requires approximately $0.4-1.0 \mathrm{~kW}$ [25].

Other process configurations, such as wetted-wall or falling liquid film reactors have been used in PPCPs degradation experiments, in the attempt to improve process efficiency. Krause tested an aluminum oxide-coated, rotating drum electrode, with the solution flowing on its outer surface as a thin film (Figure 3A), while Magureanu used a dielectric barrier discharges (DBD) unit with falling film (Figure 3B) [26,27]. Some recent developments in plasma technology include combination of atmospheric pressure plasma and photocatalysts (e.g., $\mathrm{TiO}_{2}$ ) for microorganisms control in aqueous solutions [28].

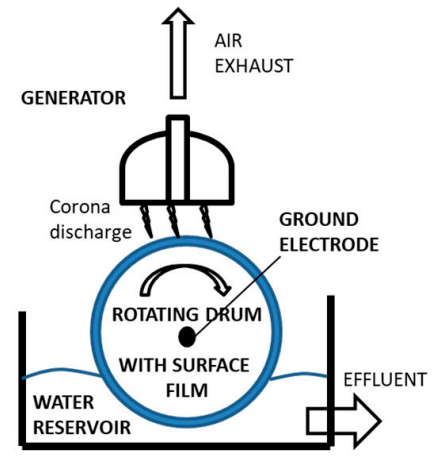

A) ROTATING DRUM

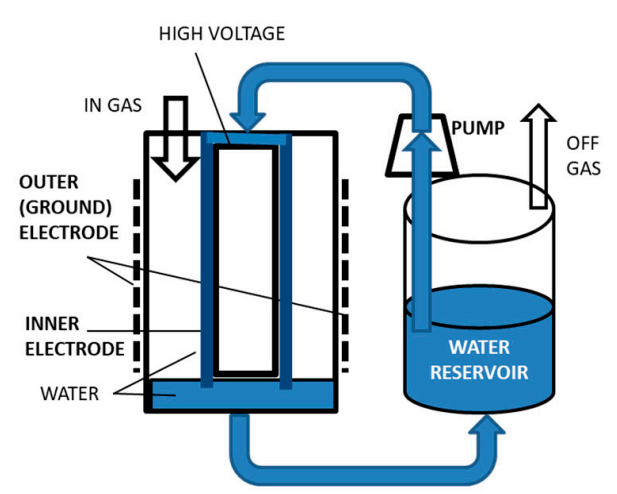

B) DIELECTRIC BARRIER DISCHARGE UNIT

Figure 3. (A) Rotating drum film, corona discharge NTP unit (B) DBD unit with falling film. dielectric barrier discharges (DBD). 


\subsubsection{Plasma Process Kinetics}

Results obtained on pharmaceutical compounds removal by NTP show that, with respect to their degradation, percent removal ratios can be represented by the following equation:

$$
R=\left(1-\frac{c}{C_{0}}\right) \times 100
$$

with $c_{0}$ and $c$ being the initial and final concentrations of a solute, respectively.

Degradation efficiency (percent) is determined according to the energy yield (i.e., compound mass removed per unit energy spent) as:

$$
Y=\frac{C_{0} \cdot V \cdot R}{P . t} \times \frac{1}{100}
$$

where $V$ is the solution volume (L), $R$ the removal ratio (\%), $P$ the discharge power $(\mathrm{kW})$ and $t$ the HRT (h).

The effects of operating parameters on NTP pollutant degradation performance have been investigated, showing that removal efficiency, intensity of electric field, shock waves and UV radiation generally increase with increasing peak voltage, with increased amounts of reactive species in both gas phase and aqueous solution. HRTs range usually around 8-30 min, depending on applied voltage and required efficiency.

Similarly to EB, plasma generates reactive species $\left(\mathrm{O}_{3}, \mathrm{OH}\right.$ and $\left.\mathrm{H}_{2} \mathrm{O}_{2}\right)$ that degrade organic molecules. Since usually the discharge occurs in ambient air, $\mathrm{O}_{3}$ is the main oxidant generated that is transferred to the liquid phase. Two mechanisms of $\mathrm{O}_{3}$ reactions may occur: direct (oxidative) or indirect (conversion to $\cdot \mathrm{OH}$, which oxidizes organics); the latter is favored by high $\mathrm{pH}$, while the former prevails in acidic conditions. Dissolved ozone in fact may cause slow $\cdot \mathrm{OH}$ formation by $\mathrm{H}_{2} \mathrm{O}_{2}$ decomposition at low $\mathrm{pH}$, but this reaction is strongly accelerated at $\mathrm{pH}>5.0$. Direct ozone oxidation of micro-pollutants is quite efficient for those compounds containing functional groups (amino groups, aromatics, double bonds). As in EB processes, removal efficiency is higher in ultrapure and tap water and lower in complex solutions (e.g., landfill leachate) at equal HRTs. This may be not only due to the competition among solutes to consume the reactive species during the process (as seen for EB), but also to the generally higher conductivity of a complex solution, which makes it difficult to sustain strong electric fields and plasma channels, or produce reactive species due to more charged ions present [29].

\section{Results}

This section summarizes literature-reported application results of EB and NTP process technology, at laboratory and full scales (if available) either as stand-alone, one-step treatment, combined to additional conventional processes, or complemented by addition of chemicals or catalyzers (to enhance process efficiency) for the removal of CECs from water and wastewater.

\subsection{EB Application Case Studies}

Significant examples of EB irradiation include, so far, a full-scale treatment facility for textile wastewater in South Korea treating a flow of 10,000 $\mathrm{m}^{3} /$ day. The facility consists of a high-power electron accelerator $(1 \mathrm{MeV}, 400 \mathrm{~kW})$ operated since 2005 at irradiation doses of 1-2 kGy added to the existing industrial biological treatment plant to achieve partial organic compound degradation. This allows to obtain a more readily biodegradable wastewater, without the use of chemical additives, by radiolytic transformation of refractory compounds into easily biodigestible forms. Irradiation before biological treatment resulted in a dramatic reduction of chemical reagent and biological process time requirements, with up to $40 \%$ increased efficiency of $\mathrm{COD}$ and $\mathrm{BOD}_{5}$ removal, compared to the original (EB-less) plant configuration [30]. Required purification levels, that were earlier obtained without irradiation after $17 \mathrm{~h}$ of biological processes, with the aid of chemicals additives, were then achieved after just $8 \mathrm{~h}$ of combined irradiation and biological treatment. 
Application of low irradiation doses (2-3 kGy) proved to decompose the entire spectrum of alkylphenolic molecules (potential estrogens) simultaneously removing surfactants (ionic and non-ionic) in urban sewage treatment plant effluents [31].

In agreement with reported evidence, it was postulated that water EB radiolysis could be an alternative to other AOPs [15]. Elimination of diclofenac (DCF) from WWTP effluent by irradiation at $1.5 \mathrm{kGy} / \mathrm{h}$ was studied [32]. At 1-kGy dose, about 50\% of chemical oxygen demand (COD) was already removed, and complete degradation of DCF and of its first-step by-products was achieved. However, as DCF is a medium-toxic compound, solution toxicity remained basically unchanged. Increasing absorbed dose, further toxicity decrease could be observed, while complete mineralization required irradiation doses up to 5-10 Gy.

While the high efficiency of energy conversion and radical generation of EB makes it a possible standalone process, it was shown that addition of between 3-12\% concentrations of $\mathrm{H}_{2} \mathrm{O}_{2}$ to the treated solutions could increase degradation rates by promoting enhanced generation of $\cdot \mathrm{OH}$ radicals [33]. An efficiency improvement of about $10 \%$ was achieved with $3 \%$ peroxide addition, but after that the level decreased significantly. In fact, when the peroxide dosage exceeds its optimal value, it reacts with hydroxyl radicals, to generate the weaker radical $\mathrm{HO}_{2}$, resulting in an overall decrease of efficiency. The presence of $\mathrm{CH}_{3} \mathrm{OH}$ and thiourea also reduced significantly DCF degradation, as the former acts as a $\cdot \mathrm{OH}$ scavenger and the latter as scavenger of $\cdot \mathrm{H}$, and $\mathrm{e}_{\mathrm{aq}}{ }^{-}$, since DCF degradation may occur both by oxidation and reduction.

Radiolytic decomposition of CBZ and DCF in river and hospital waters spiked with those compounds, with simultaneous monitoring of toxicity changes, showed that at initial DCF concentration of $50 \mathrm{mg} / \mathrm{L}$, its decomposition in aerated solution required a $4.0 \mathrm{kGy}$ dose. Saturating the solution with $\mathrm{N}_{2} \mathrm{O}$, which substantially increases hydroxyl-radical production, the required dose dropped to $1 \mathrm{kGy}$. Irradiation of hospital effluent spiked with $10 \mu \mathrm{g} / \mathrm{L}$ each of DCF and CBZ, with absorbed doses up to $0.5 \mathrm{kGy}$ showed complete decomposition of DCF at $0.25 \mathrm{kGy}$, while decomposition of carbamazepine required much larger doses than in river water samples. A 100-Gy dose allowed 90\% CBZ decomposition in the latter, but only by $37 \%$ in hospital effluents. For DCF, complete decomposition in river waters was obtained at 100-Gy, while in hospital effluents 250 Gy were needed [34].

\subsection{NTP Application Case Studies}

Tests on decomposition of endocrine disrupting chemical $17 \beta$-estradiol (E2) in different aqueous solutions (ultrapure and tap water, landfill leachate) by non-thermal plasma were reported by Gao et al. [29]. After 30 min treatment with maximum voltage of $12 \mathrm{kV}$ at $\mathrm{pH} 5.6,100 \%$ removal was achieved from an initial compound concentration of $100 \mu \mathrm{g} / \mathrm{L}$ in ultrapure water (Figure $4 \mathrm{a}-\mathrm{c}$ ). Figure 4 summarizes experimental results in the different conditions: Figure 4a illustrates the effect of peak voltage at $\mathrm{E} 2_{0}=100 \mu \mathrm{g} / \mathrm{L}$ and $\mathrm{pH} 5.6$, Figure $4 \mathrm{~b}$ the effect of initial concentration $\left(\mathrm{V}_{\max }=12 \mathrm{kV}, \mathrm{pH} 5.6\right)$, Figure $4 \mathrm{c}$ shows the effect of $\mathrm{pH}$ value $\left(\mathrm{V}_{\max }=12 \mathrm{kV}, \mathrm{E} 2_{0}=100 \mu \mathrm{g} / \mathrm{L}\right)$, Figure $4 \mathrm{~d}$ describes the effect of different solution matrices $\left(\mathrm{V}_{\max }=12 \mathrm{kV}, \mathrm{E} 2_{0}=100 \mu \mathrm{g} / \mathrm{L}, \mathrm{pH}\right.$ 5.6), clearly showing the interferences with the process due to the complex nature of the landfill leachate solution.

Gerrity et al. [35] studied the degradation of trace organic compounds such as PPCPs and endocrine disrupting chemicals (meprobamate, dilantin, primidone, carbamazepine, atenolol, trimethoprim) by pilot-scale non-thermal plasma (NTP) AOP at $500 \mathrm{~Hz}$ frequency and $8.0 \mathrm{kV}$ voltage, in tertiary effluents and spiked surface water. Trimethoprim and carbamazepine were highly susceptible to NTP treatment, while dilantin and atenolol degraded more slowly.

Meprobamate, a compound known to be highly resistant to chlorination and ozonation, required nearly double the energy to degrade to the specified level. Primidone, although not as resistant as the former, showed slower and more variable degradation than the other compounds. Contrary to EB, which may cause TOC reduction due to the extended mineralization carried out by highly energy intensive radicals, no TOC significant change was observed over the duration of the experiment. This may be 
a cause of the process' limited energy consumption, low achieved dissolved $\mathrm{O}_{3}$ concentrations, and limited ozone contact time in the NTP reactor.
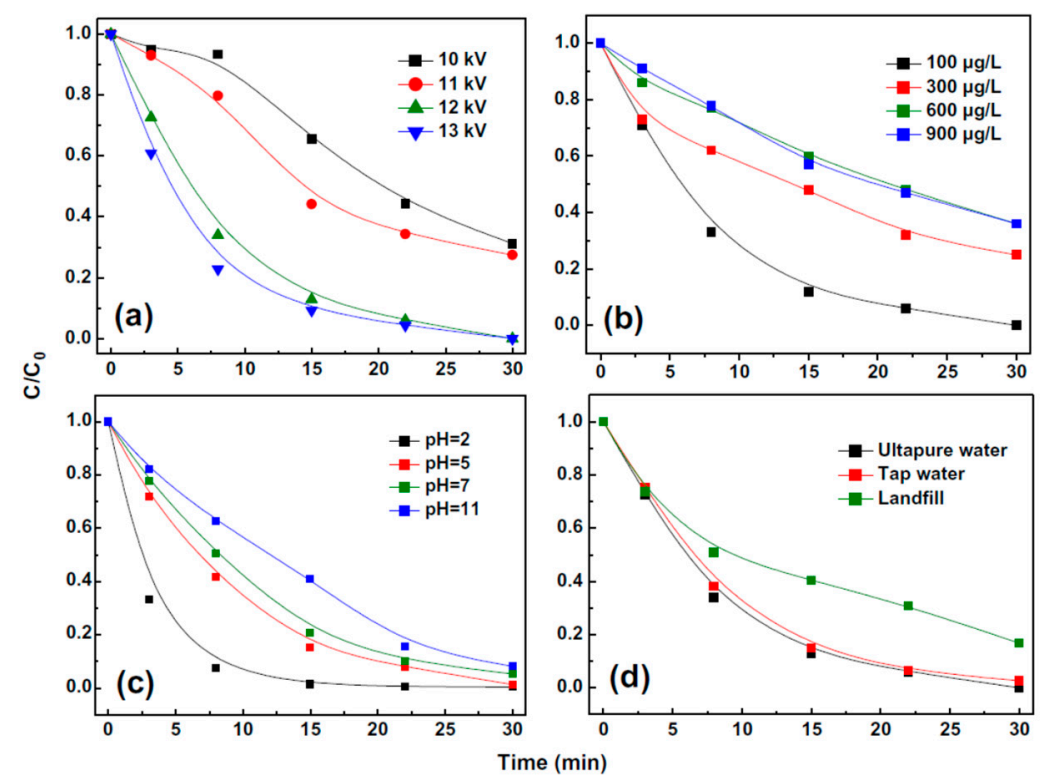

Figure 4. Effect of different parameters on E2 removal efficiency after treatment time of $30 \mathrm{~min}$, showing the interferences with the process due to the complex nature of a landfill leachate solution (a) effect of peak voltage at E2 $2_{0}=100 \mu \mathrm{g} / \mathrm{L}$ and $\mathrm{pH} 5.6$; (b) effect of initial concentration $(\mathrm{Vmax}=12 \mathrm{kV}$, $\mathrm{pH}$ 5.6); (c) effect of $\mathrm{pH}$ value $(\mathrm{Vmax}=12 \mathrm{kV}, \mathrm{E} 20=100 \mu \mathrm{g} / \mathrm{L})$; (d) effect of different solution matrices $(\mathrm{Vmax}=12 \mathrm{kV}, \mathrm{E} 20=100 \mu \mathrm{g} / \mathrm{L}, \mathrm{pH} 5.6)$ [29].

In addition NTP has shown capacity for N-nitrosodimethylamine (NDMA) destruction, a potent carcinogen in animals classified as probable carcinogen to humans through water ingestion [21]. Magureanu et al. reported results of a literature review on degradation of PPCPs by non-thermal plasma [14]. Table 5 summarizes some of the data presented by those authors. Different values for the same compound may reflect experimental uncertainty, or non-factored operating conditions of experiments.

Table 5. Summary of results reported on pharmaceuticals degradation by NTP.

\begin{tabular}{ccccc}
\hline \multirow{2}{*}{ Removal \% } & Compound $\left(\mathbf{C}_{\mathbf{0}}-\mathbf{\mu g} / \mathbf{L}\right)$ & $\begin{array}{c}\text { Discharge } \\
\text { Power (W) }\end{array}$ & HRT (min) & Comments \\
\hline \multirow{5}{*}{100} & Amoxicillin (100) & 2 & 10 & TOC removal 22.5\% (after 120 min HRT) \\
\cline { 2 - 5 } & Ampicillin (n.a.) & $=$ & 30 & TOC removal 29\% (after 120 min HRT) \\
\cline { 2 - 5 } & Oxacillin (n.a.) & $=$ & 30 & TOC removal 25\% (after 120 min HRT) \\
\cline { 2 - 5 } & Clofibric acid (21.5) & 500 & 30 & TOC removal 50\% (after 30 min HRT) \\
\cline { 2 - 5 } & Diclofenac (50) & 24 & 15 & TOC removal 27\% (after 30 min HRT) \\
\cline { 2 - 5 } & Paracetamol (100) & 250 & 20 & TOC removal 37\% (after 20 min HRT) \\
\cline { 2 - 5 } & Indomethacin (90) & 250 & 5 & TOC removal 23\% \\
\cline { 2 - 5 } & Sulfadiazine (10) & 100 & 27 & TOC removal 0\% \\
\cline { 2 - 5 } $95-99$ & Iopromide (79.1) & 500 & $30-60$ & TOC removal 17.5\% \\
\cline { 2 - 5 } & Iopromide (17) & 2.5 & 10 & $=$ \\
\cline { 2 - 5 } & Enalapril (50) & 2 & 120 & Carbamazepine (23.6) \\
\cline { 2 - 5 }
\end{tabular}


Table 5. Cont.

\begin{tabular}{ccccc}
\hline \multirow{2}{*}{ Removal \% } & Compound $\left(\mathbf{C}_{\mathbf{0}}-\boldsymbol{\mu g} / \mathbf{L}\right)$ & $\begin{array}{c}\text { Discharge } \\
\text { Power (W) }\end{array}$ & HRT (min) & Comments \\
\hline \multirow{3}{*}{$90-94$} & Carbamazepine (20) & 12 & 60 & TOC removal 19.4\% \\
\cline { 2 - 5 } & Pentoxifylline (100) & 1.2 & 60 & $=$ \\
\cline { 2 - 5 } & Ibuprofen (60) & 3 & 80 & TOC removal 34\% (after 180 min HRT) \\
\hline \multirow{3}{*}{$80-90$} & Sulfadiazine (10) & 100 & 15 & TOC removal 25\% (after 30 min HRT) \\
\cline { 2 - 5 } & Tetracycline (50) & 36 & 15 & TOC removal 53.4\% \\
\cline { 2 - 5 } & Ibuprofen (110) & 250 & 30 & TOC removal 32\% \\
\hline \multirow{2}{*}{$60-70$} & Tetracycline (50) & 36 & 24 & TOC removal 23.5\% \\
\cline { 2 - 5 } & B-Oestradiol (3) & 120 & 30 & $=$ \\
\hline
\end{tabular}

\subsection{Energetic Considerations}

An indicator of energy efficiency of a process is represented by the "electrical energy per order" (EEO), which has been defined as the amount of $\mathrm{kWh}$ 's required to reduce a pollutants' concentration by one order of magnitude (i.e., on $\log$ or $90 \%$ ) in $1 \mathrm{~m}^{3}$ of solution [36]. EEO values are thus expressed as $\mathrm{kWh} \mathrm{m}^{-3}$ order $^{-1}$ (also indicated as $\mathrm{kWh} \mathrm{m}^{-3} \log ^{-1}$ ), and are used to compare technologies for a given degradation reaction, even if based on published reports and articles from different periods, independently of actual energy prices. Depending on process type, pollutant and its initial concentration, reported EEO values range between 0.6 to above 300 . The more efficient the process in the removal of a pollutant, the lower will be the calculated EEO value, however this value can be affected also by the specific composition of the water matrix, hence it may be different for the same contaminant in different conditions. As shown in Figure 5 [36] EEO values for the same compound may vary substantially between pure (monocomponent) and complex (multicomponent) solutions. In case of ozonation, for example, variability could be explained by water matrix interference on radical formation: radical scavenging and water matrix composition could directly affect generation and interaction of radicals, hence application of the EEO index to compare of experimental results obtained from different solution matrices is not recommended. An important caveat of EEO is that it evaluates an entire system, hence all aspects of reactor and reaction are expressed in a single metric. Another important one is that EEO does not take into account the cost or efficiency of obtaining reagents. However, properly determined EEO values, in addition to allow quick and simple technology comparison, may provide information for processes scale-up, as well as for sustainability analysis [37].

Given the above caveats, EEO should only be determined for processes that are already optimized, and demand for auxiliary external oxidants should be included in the EEO estimation by considering any additives as "stored electric energy", however, the majority of studies are limited to considering the electricity used directly in the process. For example, a Fenton reaction's unique power requirement is for solution stirring, however, it requires peroxide addition to occur, but EEO is not able to reflect the costs (certainly not the monetary cost, and perhaps-depending on methodology-not even the energetic-equivalent) of peroxide dosing necessary to operate it.

In order to make some comparisons among processes, some examples are reported below. Degradation of a mix of micropollutants (atrazine, NDMA, MTBE, dioxane, bisphenol A, microcystine, diclofenac, ibuprofen) by $\mathrm{UV} / \mathrm{H}_{2} \mathrm{O}_{2}$ from supply water in a Dutch water treatment plant showed, under optimized conditions, EEOs in the range 1.08-2.84 [38]. In that case, only $8-14 \%$ of the energy input could be attributed to electrochemical production of $\mathrm{H}_{2} \mathrm{O}_{2}$, while the rest is required to operate the low pressure UV lamps. Compounds with lower reaction rates with $\cdot \mathrm{OH}$, or not responding to photolysis, would register higher EEOs at similar treatment levels. Other researchers reported, for a similar process, EEO values of 0.17 for diclofenac removal, and of 0.62 for Carbamazepine removal [39]. 


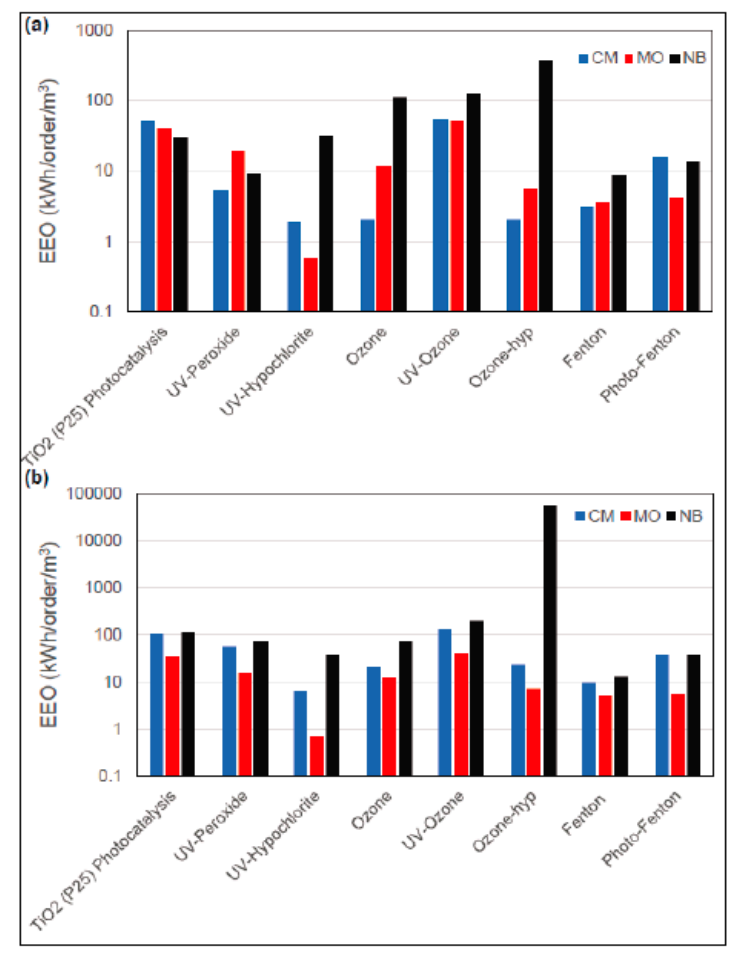

Figure 5. Observed EEO values for different AOPs in monocomponent (a) and multicomponent (b) solutions. Legend: $\mathrm{CM}=$ carbamazepine, $\mathrm{MO}=$ methyl orange, $\mathrm{NB}=$ nitrobenzene (from [36]). Advanced Oxidation Processes (AOPs).

Strong EEO value variations can be observed between various groups of "conventional" AOPs: $\mathrm{O}_{3}, \mathrm{O}_{3} / \mathrm{H}_{2} \mathrm{O}_{2}, \mathrm{O}_{3} / \mathrm{UV}, \mathrm{UV} / \mathrm{H}_{2} \mathrm{O}_{2}, \mathrm{UV} /$ persulfate, $\mathrm{UV} /$ chlorine record median $\mathrm{EEO}$ values of $<1$, while photo-Fenton and electrolytic AOPs have considerably higher EEOs (in the range of 1-100). UV-based photocatalysis, ultrasound, and microwave AOPs show median values $>100$. Besides matrix type, a major influence factor in EEO determination is process capacity (i.e., laboratory, pilot and full-scale applications) and specific equipment used. For example, in case of processes involving UVs, actual lamp type proved to have a significant influence on EEO determination [40].

In water radiolysis processes, absorbed (radiation) energy is usually given in kGy and this can be easily used for any radiation source (gamma and EB). In practical water treatment applications, however, instead of gamma sources, electron accelerators are normally used due to their superior practical characteristics. In modern electron accelerators for water and wastewater treatment, $75 \%$ of electric energy is converted to accelerated electrons' energy, therefore, the EEO calculated based on input energy, can be corrected by dividing it by 0.75 [40].

Comparison of EEO values for imidacloprid degradation using $\mathrm{TiO}_{2}$ photocatalysis $\left(\mathrm{TiO}_{2} 1 \mathrm{~g} / \mathrm{L}\right)$, radiolysis and UV/VUV photolysis showed high values for UV $($ EEO = 60), lower for both UV/VUV (combination of UV at $254 \mathrm{~nm}$ and VUV at $185 \mathrm{~nm}$ ) and $\mathrm{TiO}_{2} / \mathrm{UV}$ (15) and extremely low for radiolysis (0.25) [41]. Considering the fact that EB requires only direct energy consumption (no "stored energy" components) and its technology has intrinsic high conversion efficiency (input electric to output radiation energy), EB could be considered one of the most efficient AOPs currently available, with energy demand smaller by approximately two order of magnitude as those of other methods. Process yield efficiency in radical generation, based on energy output, was estimated at $1.0 \mathrm{M} / \mathrm{kWh}$ for EB, while the yield is $1.4 \mathrm{M} / \mathrm{kWh}$ for $\mathrm{UV} / \mathrm{H}_{2} \mathrm{O}_{2}$ and 0.087 for $\mathrm{UV} / \mathrm{TiO}_{2}$ [42]. In addition to the higher radical yield, EB as mentioned earlier, produces a wider variety of radicals, both oxidating and reducing, some of which with greater reactivity.

For NTP processes applications, reported EEO values ranged from $<0.3$ for carbamazepine and similar easily degraded compounds in surface water (about 50\% less than for UV-peroxide processes), 
to 14 for recalcitrant compounds (e.g., meprobamate) in wastewater [35]. Other researchers reported EEO values for degradation of different pharmaceuticals in the range 27-430 [43]. Table 6 shows EEO values for different experiments in PPCPs and EDCs degradation with different NTP technologies, photolysis, $\mathrm{UV} / \mathrm{H}_{2} \mathrm{O}_{2}$, and photocatalysis on similar water matrices [35]. As indicated by data, NTP was generally more efficient than the other tested processes for each compound, comparable to $\mathrm{UV} / \mathrm{H}_{2} \mathrm{O}_{2}$ at peroxide dose of $10 \mathrm{mg} / \mathrm{L}$. It is however significant that NTP does not use UV lamps (subject to maintenance and replacement) or expensive peroxide addition to generate oxidative species, therefore it could be considered a viable alternative to more common processes.

Table 6. Specific EEO values for different AOPs applied to some contaminants of interest on the same water matrix (spiked Lake Mead surface water, $\mathrm{kWh} \mathrm{m}^{-3}$ order $^{-1}$ ) (data from [34]).

\begin{tabular}{|c|c|c|c|c|}
\hline Contaminant & $\begin{array}{c}\text { NTP a } \\
\text { Range (mean) }\end{array}$ & $\mathbf{U V}^{\mathrm{b}}$ & $\mathrm{UV} / \mathrm{H}_{2} \mathrm{O}_{2}{ }^{b, c}$ & $\mathrm{UV} / \mathrm{TiO}_{2}{ }^{\mathrm{b}, \mathrm{d}}$ \\
\hline Meprobamate & $2.1-5.3(3.5)$ & 6.6 & 1.0 & 6.8 \\
\hline Dilantin & $1.1-3.1(2.0)$ & 2.1 & 1.0 & 3.1 \\
\hline Primidone & $1.1-3.3(2.2)$ & 3.7 & 0.3 & 3.9 \\
\hline Carbamazepine & $0.3-1.2(0.7)$ & 2.3 & 0.4 & 2.1 \\
\hline Atenolol & $0.4-1.7(1.0)$ & 1.4 & 0.5 & 2.0 \\
\hline Trimethoprim & $0.3-1.2(0.7)$ & 0.8 & 0.4 & 1.5 \\
\hline Atrazine & $2.2-6.3(3.7)$ & 3.3 & 1.2 & 4.7 \\
\hline
\end{tabular}

a For nine different scenarios with generators ranging from 0.6 to $2.6 \mathrm{kWh} / \mathrm{m}^{3}$ and frequency $500-800 \mathrm{~Hz}$;

b 32 amalgam UV lamps, each rated at $12 \mathrm{~mW} / \mathrm{cm}^{2}, 38 \%$ conversion efficiency; ${ }^{c}$ peroxide concentration $10 \mathrm{mg} / \mathrm{L}$;

d $\mathrm{TiO}_{2}$ concentration $500 \mathrm{mg} / \mathrm{L}$.

Table 7 reports EEO values determined for different AOPs [37]. These figures are only indicative, as it should be remembered that these numbers measure the energy output of the process devices, and do not take into account their energy conversion efficiency, which may vary from 30 to $80 \%$, nor the "stored energy" contained in added chemicals and catalysts.

Table 7. Summary of published EEO-values of different AOPs (range and median values).

\begin{tabular}{|c|c|c|}
\hline AOP Type & $\begin{array}{c}\text { EEO Range } \\
{\left[\mathrm{kWh} \mathrm{m}^{-3} \text { Order }^{-1}\right]}\end{array}$ & $\begin{array}{l}\text { EEO Median Value } \\
{\left[\mathrm{kWh} \mathrm{m}^{-3} \text { Order }^{-1}\right]}\end{array}$ \\
\hline Ozonation & $0.07-0.3$ & 0.15 \\
\hline $\mathrm{O}_{3} / \mathrm{H}_{2} \mathrm{O}_{2}$ & $0.1-1.5$ & 0.2 \\
\hline $\mathrm{EB}$ & $0.2-1$ & 0.3 \\
\hline $\mathrm{UV} / \mathrm{Cl}$ & $0.2-0.7$ & 0.4 \\
\hline UV/persulfate & $0.2-1.1$ & 0.67 \\
\hline $\mathrm{O}_{3} / \mathrm{UV}$ & $0.25-1$ & 0.7 \\
\hline $\mathrm{UV} / \mathrm{H}_{2} \mathrm{O}_{2}$ & $0.3-1.2$ & 0.75 \\
\hline Photo-Fenton & $1.1-10$ & 2.6 \\
\hline Plasma (any) & $1.1-12$ & 3.3 \\
\hline e-AOPs & $10-70$ & 38 \\
\hline UV/catalyst & $150-450$ & 335 \\
\hline Microwave & $500-700$ & 540 \\
\hline Ultrasound & $800-8000$ & 2600 \\
\hline
\end{tabular}

Table 8 summarizes reported total cost-of-treatment (CoT) estimates for AOP technologies applied to (municipal) wastewater disinfection (to below detection limits of pathogens). While specific cost of chlorination remains constant (the cost is essentially based on chemical cost), that of other technologies diminishes with increasing treated flow (due to initial fixed costs). Among the technologies examined $\left(\mathrm{EB}, \mathrm{O}_{3}\right.$ and UV), EB is the one with the steepest cost decline with treated flow [44]. 
Table 8. Estimated costs comparison for disinfection of sewage water (2010 US $\$ / \mathrm{m}^{3}$ ).

\begin{tabular}{ccccc}
\hline $\mathbf{m}^{\mathbf{3}}$ /day Treated & Electron Beam & Ozone & UV & Chlorine \\
\hline 10,000 & 0.29 & 0.25 & 0.17 & 0.013 \\
50,000 & 0.073 & 0.086 & 0.171 & 0.013 \\
100,000 & 0.050 & 0.064 & 0.054 & 0.013 \\
200,000 & 0.041 & 0.053 & 0.047 & 0.013 \\
\hline
\end{tabular}

It should be noted that the EB process showed, at the same time, substantial improvements in effluent water due to efficient further degradation of organic load (on irradiation, residual organic matter in the effluent is subject to exposure to radicals' action in greater amounts than with other technologies). This may imply an advantage in case of effluent reuse for irrigation, as water will contain simpler molecular organic forms that could be more easily metabolized by native soil microflora during land distribution.

\section{Discussion}

This review paper provides a comparative summary of innovative, emerging AORPs (EB and NTP) versus currently adopted AOPs. To facilitate process efficiency comparison, data concerning reported EEO values for each technology were gathered from the analysis of literature articles. The EEO concept provides an initial parameter that may help to directly evaluate and compare AOPs based on energy efficiency, notwithstanding strong limitations to its use linked to the variability of all influencing factors in its determination. Despite a high dispersion of reported data, a significant trend of difference among AOPs' efficiency, as measured by EEO, could be observed. Regarding economic considerations alone, referred to EEO values, radiolysis appears to be the most suitable technique [41]. Considering traditional AOPs, EEO values for $\mathrm{UV} / \mathrm{H}_{2} \mathrm{O}_{2}$ are much lower than those for $\mathrm{UV}$ and photocatalysis; at the same time, UV techniques have generally higher energy consumption, and are less efficient in elimination of degradation by-products. Although EB and NTP applications achieved comparable or better efficiencies to those of $\mathrm{UV} / \mathrm{H}_{2} \mathrm{O}_{2}$, the best practical alternative for a particular situation will depend mainly on reliability, robustness and cost.

Radiation-based treatment technology by EB generally represents a potential, environmentally friendly alternative to traditional AOPs, without use of chemicals, minimal by-products generation and absence of DBPs in water disinfection (in conventional chlorination, toxic organo-chlorine products, mutagenic and carcinogenic, may occur). Because of simultaneous generation of oxidizing and reducing radicals, ionizing radiation methods are recognized as some of the most versatile AORPs, able to degrade a wide variety of pollutant in solution, with the technical possibility of achieving complete mineralization. EB technology has also shown higher radical-generating efficiency than ozone-based processes. Their efficiency could be further substantially increased, reducing input energy requirements, by combining them with different catalysts or biological processes in hybrid AORPs processes. Although there are many successful pilot-scale literature reports of radiolytic technologies, these have been tested on full-scale, long running applications only in a few reported instances.

NTP technology has only very recently been tested for treatment of contaminants in solution, and even with several reported success experimental applications, and demonstrated low energy requirements, it is still regarded as a niche field. Recent studies showed efficacy of NTP in PPCPs and EDCs (trichloroethylene-TCE, N-nitrosodimethylamine-NDMA, 1,4-dioxane, and methyl tert-butyl ether-MTBE) degradation in pilot batch experiments [25]. Currently, NTP technology has still limited commercial availability and has not been tested in full-scale settings, so its long-term performance is still undetermined. In addition, its application is currently limited to low-flow setups, due to its thin-film configuration constraints.

In reported literature, studies concerning all types of AOPs are most often conducted with high-purity laboratory-spiked solutions, representing very different situations from the real world, in which wastewater, grey water, and even tap water will contain a variety of ions, minerals, and organic 
compounds. These may act as radical scavengers in the solution, reducing the number of radicals available to carry out pollutants degradation, increasing the input energy required to remove to the same level a given contaminant from a "pure" solution. All mechanisms of contaminants removal by AOPs will all be affected by such conditions, and extensive tests on actual solutions are required before any such system can be implemented. Since AORPs (and in particular EB) are capable to deliver higher amounts of energy in short intervals, they are however unlikely to suffer insurmountable limitations in terms of final degradation results. Some of the important subtleties that must be considered when developing AOP treatment systems include also reactions cross-interferences in multi-contaminant mixtures, creation of recalcitrant/toxic by-products, and the ability of combined processes to improve effectiveness compared to a singlehanded approach.

True capital costs of full-scale EB and NTP water and wastewater treatment are still relatively unclear, even though they have shown greater energy efficiency than conventional AOPs. To this uncertainty certainly contributed the "industrial effect" of technology availability. In water-related applications, EB technology-although more mature than NTP-is in its infancy compared to consolidated UV or ozone technology, even though is currently being applied in many other industrial sectors requiring fast and economic capability of molecular modification of chemical bonds. In the author's opinion, there is no doubt that the cost of EB and plasma machines will be driven to lower levels with increasing diffusion and technological improvement, as previously seen with UV and ozone technologies.

\section{Conclusions}

Recent experimental applications of EB and NTP technologies for the treatment of specific refractory or hard-to-treat pollutants, in particular CECs, in water and wastewater have sprouted in the technical literature, with positive outcomes, although mostly at small-scale. These may represent cleaner, alternative treatment methodologies, as environmentally friendly solutions without use of chemicals and high efficiency, favoring possibilities for water reuse not only in irrigation but also for more demanding uses. The characteristics of these advanced technologies minimize some of the drawbacks of traditional AOPs, such as: extended process contact times, lack of full mineralization in operating conditions, generation of by-products with largely unknown effects, chemicals' addition to achieve acceptable efficiency, production of process residues (e.g., spent PAC, nanoparticles, process sludge), issues with operators' safety, but are not sufficiently field-proven to encourage widespread adoption. Further investigations on the economic balance of these new processes applications are needed, although current initial estimates seem to validate a rationale for their use.

While more practical demonstrative applications are needed, the current trend of introducing mandatory treatment of CECs and EDCs in waters and wastewater in many countries, may soon require new and more efficient removal technologies. AORP processes may soon become a winning and final strategy for the solution of this generalized contamination problem.

Funding: This research received no external funding.

Conflicts of Interest: The author declares no conflict of interest.

\section{References}

1. Daughton, C.G.; Jones-Lepp, T. Pharmaceuticals and Personal Care Products in the Environment-Scientific and Regulatory Issues; ACS Symposium Series; American Chemical Society: Washington, DC, USA, 2001; Volume 791.

2. Copetti, D.; Marziali, L.; Viviano, G.; Valsecchi, L.; Guzzella, L.; Capodaglio, A.G.; Tartari, G.; Polesello, S.; Valsecchi, S.; Mezzanotte, V.; et al. Intensive monitoring of conventional and surrogate quality parameters in a highly urbanized river affected by multiple combined sewer overflows. Water Sci. Tech. Water Supply 2018, 19, 953-966. [CrossRef] 
3. US EPA. Contaminants of Emerging Concern Including Pharmaceuticals and Personal Care Products. 2016. Available online: https://www.epa.gov/wqc/contaminants-emerging-concern-including-pharmaceuticalsand-.personal-care-products (accessed on 15 May 2017).

4. Capodaglio, A.G.; Bojanowska-Czajka, A.; Trojanowicz, M. Comparison of different advanced degradation processes for the removal of the pharmaceutical compounds diclofenac and carbamazepine from liquid solutions. Env. Sci. Poll. Res. 2018, 25, 27704-27723. [CrossRef]

5. Capodaglio, A.G. In-stream detection of waterborne priority pollutants, and applications in drinking water contaminant warning systems. Water Sci. Tech. Water Supply 2017, 17, 707-725. [CrossRef]

6. Lee Ventola, C. The Antibiotic Resistance Crisis Part 1: Causes and Threats. Pharm. Ther. 2015, 40, $277-283$.

7. Petrovic, M.; Gonzalez, S.; Barcelo, D. Analysis and removal of emerging contaminants in wastewater and drinking water. Trends Anal. Chem. 2003, 22, 685-696. [CrossRef]

8. Jelic, A.; Gros, M.; Ginebreda, A.; Cespedes-Sanchez, R.; Ventura, F.; Petrovic, M.; Barcelo, D. Occurrence, partition and removal of pharmaceuticals in sewage water and sludge during wastewater treatment. Water Res. 2011, 45, 1165-1176. [CrossRef] [PubMed]

9. Wu, Q.; Shi, H.; Adams, C.D.; Timmons, T.; Ma, Y. Oxidative removal of selected endocrine-disruptors and pharmaceuticals in drinking water treatment systems, and identification of degradation products of triclosan. Sci. Total Environ. 2012, 439, 18-25. [CrossRef] [PubMed]

10. Cecconet, D.; Molognoni, D.; Callegari, A.; Capodaglio, A.G. Biological combination processes for efficient removal of pharmaceutically active compounds from wastewater: A review and future perspectives. J. Environ. Chem. Eng. 2017, 5, 3590-3603. [CrossRef]

11. Esplugas, S.; Bila, D.M.; Krause, L.G.T.; Dezotti, M. Ozonation and advanced oxidation technologies to remove endocrine disrupting chemicals (EDCs) and pharmaceuticals and personal care products (PPCPs) in water effluents. J. Hazard. Mater. 2007, 149, 631-642. [CrossRef]

12. Klavarioti, M.; Mantzavinos, D.; Kassinos, D. Removal of residual pharmaceuticals from aqueous systems by advanced oxidation processes. Environ. Int. 2009, 35, 402-417. [CrossRef]

13. Capodaglio, A.G. Could EB irradiation be the simplest solution for removing emerging contaminants from water and wastewater? Water Pract. Tech. 2018, 13, 172-183. [CrossRef]

14. Magureanu, M.; Mandache, N.B.; Parvulescu, V.I. Degradation of pharmaceutical compounds in water by non-thermal plasma treatment. Water Res. 2015, 81, 124-136. [CrossRef] [PubMed]

15. Trojanowicz, M.; Bojanowska-Czajka, A.; Capodaglio, A.G. Can radiation chemistry supply a highly efficient $\mathrm{AO}(\mathrm{R}) \mathrm{P}$ process for organics removal from drinking and waste water? A review. Environ. Sci. Pollut. Res. 2017, 24, 20187-20208. [CrossRef] [PubMed]

16. Capodaglio, A.G. High-energy oxidation process: An efficient alternative for wastewater organic contaminants removal. Clean Technol. Environ. Policy 2017, 19, 1995-2006. [CrossRef]

17. Sanchez-Polo, M.; Lopez-Penalver, J.; Prados-Joya, G.; Ferro-Garcia, M.A.; Rivera-Utrilla, J. Gamma irradiation of pharmaceutical compounds, nitroimidazoles, as a new alternative for water treatment. Water Res. 2009, 43, 4028-4036. [CrossRef]

18. Van Dyk, J.; Macdonald, J.F.C. Penetration of high energy electrons in water. Phys. Med. Biol. 1972, 17, 52-55.

19. Buxton, G.V.; Greenstock, C.L.; Helman, W.P.; Ross, A.B. Critical review of rate constants for reaction of hydrated electrons, hydrogen atoms and hydroxyl radical $\left(\cdot \mathrm{OH} / \cdot \mathrm{O}^{-}\right)$in aqueous solution. J. Phys. Chem. Ref. Data 1987, 17, 512-887. [CrossRef]

20. Liu, Y.; Sun, Y.; Hu, J.; He, J.; Mei, S.; Xue, G.; Ognier, S. Removal of iopromide from an aqueous solution using dielectric barrier discharge. J. Chem. Technol. Biotechnol. 2013, 88, 468-473. [CrossRef]

21. Locke, B.R.; Sato, M.; Sunka, P.; Hoffmann, M.R.; Chang, J.S. Electrohydraulic discharge and nonthermal plasma for water treatment. Ind. Eng. Chem. Res. 2006, 45, 882-905. [CrossRef]

22. Pekarek, S. Non-thermal plasma ozone generation. Acta Polytech. 2003, 43, 47-51.

23. Masuda, S.; Hosokawa, S.; Tu, X.; Wang, Z. Novel plasma chemical technologies -PPCP and SPCP for control of gaseous pollutants and air toxics. J. Electrost. 1995, 34, 415-438. [CrossRef]

24. Hwang, Y.H.; Jo, Y.M. Decomposition of odorous gases in a pilot-scale nonthermal plasma reactor. J. KOSAE 2005, 21, 57-65.

25. Even-Ezra, I.; Mizrahi, A.; Gerrity, D.; Snyder, S.; Salveson, A.; Lahav, O. Application of a novel plasma-based advanced oxidation process for efficient and cost effective destruction of refractory organics in tertiary effluents and contaminated groundwater. Desalin. Water Treat. 2009, 11, 236-244. [CrossRef] 
26. Krause, H.; Schweiger, B.; Prinz, E.; Kim, J.; Steinfeld, U. Degradation of persistent pharmaceuticals in aqueous solutions by a positive dielectric barrier discharge treatment. J. Electrost. 2011, 69, 333-338. [CrossRef]

27. Magureanu, M.; Piroi, D.; Mandache, N.B.; David, V.; Medvedovici, A.; Bradu, C.; Parvulescu, V.I. Degradation of antibiotics in water by non-thermal plasma treatment. Water Res. 2011, 45, 3407-3416. [CrossRef]

28. Zhou Re Zhou Ru Zhang, X.; Li, J.; Wang, X.; Chen, Q.; Yang, S.; Chen, Z.; Bazaka, K.; Ostrikov, K. Synergistic Effect of Atmospheric-pressure Plasma and $\mathrm{TiO}_{2}$ Photocatalysis on Inactivation of Escherichia coli Cells in Aqueous Media. Sci. Rep. 2016, 6, 39552. [CrossRef]

29. Gao, L.; Sun, L.; Wan, S.; Yu, Z.; Li, M. Degradation kinetics and mechanism of emerging contaminants in water by dielectric barrier discharge non-thermal plasma: The case of $17 \beta$-Estradiol. Chem. Eng. J. 2013, 228, 790-798. [CrossRef]

30. Kuk, S.H.; Kim, S.M.; Kang, W.G.; Han, B.; Kuksanov, N.K.; Jeong, K.Y. High power accelerator for environmental applications. J. Korean Phys. Soc. 2011, 59, 3485-3488. [CrossRef]

31. Petrovic, M.; Gehringer, P.; Eschweiler, H.; Barcelo, D. Radiolytic decomposition of multi-class surfactants and their biotransformation products in sewage treatment plant effluents. Chemosphere 2007, 66, 114-122. [CrossRef]

32. Homlok, R.; Takács, E.; Wojnárovits, L. Elimination of diclofenac from water using irradiation technology. Chemosphere 2011, 85, 603-608. [CrossRef]

33. Liu, Q.; Luo, X.; Zheng, Z.; Zheng, B.; Zhang, J.; Zhao, Y.; Yang, X.; Wang, Y.; Wang, L. Factors that have an effect on degradation of diclofenac in aqueous solution by gamma ray irradiation. Environ. Sci. Pollut. Res. 2011, 18, 1243-1252. [CrossRef] [PubMed]

34. Bojanowska-Czajka, A.; Kciuk, G.; Gumiela, M.; Borowiecka, S.; Nałęcz-Jawecki, G.; Koc, A.; Garcia-Reyes, J.F.; Solpan Ozbay, D.; Trojanowicz, M. Analytical, toxicological and kinetic investigation of decomposition of the drug diclofenac in waters and wastes using gamma radiation. Environ. Sci. Pollut. Res. 2015, 22, 20255-20270. [CrossRef] [PubMed]

35. Gerrity, D.; Stanford, B.D.; Trenholm, R.A.; Snyder, S.A. An evaluation of a pilot-scale nonthermal plasma advanced oxidation process for trace organic compound degradation. Water Res. 2010, 44, 493-504. [CrossRef] [PubMed]

36. Bolton, J.R.; Bircher, K.G.; Tumas, W.; Tolman, C.A. Figures-of-merit for the technical development and application of advanced oxidation technologies for both electric- and solar-driven systems (IUPAC Technical Report). Pure Appl. Chem. 2001, 73, 627-637. [CrossRef]

37. Ambrogi, E.K.; Asenath-Smith, E.; Ballard, W.A.; Moores, L.C.; Brame, J.A. Cross-Comparison of Advanced Oxidation Processes for Remediation of Organic Pollutants in Water Treatment Systems. In ERDC 6.2 Advanced Low Logistics Water (ALL-H2O) "Task 6: Catalytic Coatings for Oxidative/Reductive Destruction of Micropolutants," Program Element 622720048, "Industrial Operations Pollution Control Guidance"; U.S. Army Corps of Engineers: Washington, DC, USA, 2019.

38. Miklos, D.B.; Remy, C.; Jekel, M.; Linden, K.G.; Drewes, J.Ö.E.; Hübner, U. Evaluation of advanced oxidation processes for water and wastewater treatment-A critical review. Water Res. 2018, 139, 118-131. [CrossRef] [PubMed]

39. Kruithof, J.C.; Kamp, P.C.; Martijn, B.J. UV/ $\mathrm{H}_{2} \mathrm{O}_{2}$ treatment: A practical solution for organic contaminant control and primary disinfection. Ozone Sci. Eng. 2007, 29, 273-280. [CrossRef]

40. Sichel, C.; Garcia, C.; Andre, K. Feasibility studies: UV/chlorine advanced oxidation treatment for the removal of emerging contaminants. Water Res. 2011, 45, 6371-6380. [CrossRef]

41. Rózsa, G.; Náfrádi, M.; Alapi, T.; Schrantz, K.; Szabó, L.; Wojnárovits, L.; Takács, E.; Tungler, A. Photocatalytic, photolytic and radiolytic elimination of imidacloprid from aqueous solution: Reaction mechanism, efficiency and economic considerations. Appl. Catal. B Environ. 2019, 250, 429-439. [CrossRef]

42. Bolton, J.R.; Valladares, J.E.; Zanin, J.P.; Cooper, W.J.; Nickelson, M.G.; Kajdi, D.C.; Waite, T.D.; Kurucz, C.N. Figures-of-merit for advanced oxidation technologies: A comparison of homogeneous $\mathrm{UV} / \mathrm{H}_{2} \mathrm{O}_{2}$, heterogeneous $\mathrm{UV} / \mathrm{TiO}_{2}$ and electron beam processes. J. Adv. Oxid. Technol. 1998, 3, 174-181. [CrossRef] 
43. Brandenburg, R.; Bogaerts, A.; Bongers, W.; Fridman, A.; Fridman, G.; Locke, B.R.; Miller, V.; Reuter, S.; Schiorlin, M.; Verreycken, T.; et al. White paper on the future of plasma science in environment, for gas conversion and agriculture. Plasma Process. Polym. 2018, 16, 1700238. [CrossRef]

44. Maruthi, Y.A.; Lakshmana Das, N.; Hossain, K.; Sarma, K.S.S.; Rawat, K.S.; Sabharwal, S. Disinfection and reduction of organic load of sewage water by electron beam radiation. Appl. Water Sci. 2011, 1, 49-56. [CrossRef]

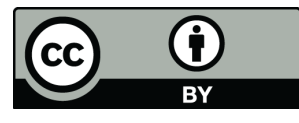

(C) 2019 by the author. Licensee MDPI, Basel, Switzerland. This article is an open access article distributed under the terms and conditions of the Creative Commons Attribution (CC BY) license (http://creativecommons.org/licenses/by/4.0/). 